\title{
Dry Aerosol Coating of Anti-viral Particles on Commercial Air Filters Using a High-volume Flow Atomizer
}

\author{
Dae Hoon Park ${ }^{1}$, Yun Haeng Joe ${ }^{2}$, Jungho Hwang ${ }^{1 *}$ \\ ${ }^{1}$ School of Mechanical Engineering, Yonsei University, Seoul 03722, Korea \\ ${ }^{2}$ Climate Change Research Division, Korea Institute of Energy Research, Daejeon 34129, Korea
}

\begin{abstract}
Filtration is a common air cleaning technique used to remove airborne particulates. However, microorganisms can survive and multiply on the filter's surface in heating, ventilation, and air-conditioning systems. These multiplied microorganisms eventually disperse in the air. The most conventional method of coating pristine air filter media with anti-viral material involves applying a wet coating via solution processing, wherein the filter media needs to be soaked in a solution containing a large amount of dispersed anti-viral material, and then drying the coated filter using a heated air flow. However, the latter step requires additional time and energy and often causes the deformation of the filter material. By contrast, applying an aerosolized coating is a dry process, wherein aerosolized anti-viral material is directly deposited on the filter at atmospheric pressure and room temperature. In this work, we design a laboratory-made atomizer to generate highly concentrated aerosolized particles at a high flow rate $\left(>200 \mathrm{~L} \mathrm{~min}^{-1}\right)$. The generated anti-viral material $\left(\mathrm{SiO}_{2}-\mathrm{Ag}\right.$ nanoparticles $)$, which includes liquid droplets, is dried by a sheath air flow and directly applied to a commercial air filter unit. The coated antiviral filter is evaluated for filtration efficiency and anti-viral activity against aerosolized MS2 bacteriophage.
\end{abstract}

Keywords: High-volume flow atomizer; Air filter; Anti-viral; Dry aerosol coating.

\section{INTRODUCTION}

The increase in human indoor activities and rapid urbanization has placed a spotlight on improving indoor air quality to remove and inactivate bioaerosols (Leung et al., 2009). In particular, recent airborne infections caused by infectious viruses have led to increased concern (Lee et al., 2003; Smith et al., 2009). Viral particles exist in the air of indoor spaces (Sawyer et al., 1994; Fabian et al., 2008; Chen et al., 2009; Loeb et al., 2009; Stelzer-Braid et al., 2009; Yang et al., 2011) and can remain suspended in the air for a long time owing to their nanometer-sizes (Wells, 1955). As average people stay indoors for most of their time (Oberdörster and Utell, 2002), development of effective air control technologies has received much attention to maintain clean indoor air quality and prevent the spread of

\footnotetext{
* Corresponding author.

Tel.: 82-2-2123-2821; Fax: 82-2-312-2821

E-mail address: hwangjh@yonsei.ac.kr
}

This article is an English version of "Development of Mass Aerosol Particle Generator and Fabrication of Commercial Anti-viral Air Filter [Korean]" published in Particle and Aerosol Research in December 2016. respiratory diseases.

Filtration is the most widely applied technique to eliminate airborne particulates from air streams. Recently, some microorganisms have been reported to grow on the filter in heating, ventilating, and air-conditioning systems (HVAC) as dust particles collected on the filter contribute as nutrients for the microorganisms (Maus et al., 2001; Verdenelli et al., 2003; Cecchini et al., 2004; Yoon et al., 2008; Miaśkiewicz-Peska and Łebkowska, 2011). The multiplied microorganisms with their microbial volatile organic compounds may be released into the air (Park and Jang, 2003; Verdenelli et al., 2003; Cecchini et al., 2004; Byeon et al., 2007). To address this issue, antimicrobial filters with prompt antimicrobial activity have been fabricated by coating air filter media with various antimicrobial agents (Sim et al., 2015; Taylor et al., 2016; Choi et al., 2018; Pokhum et al., 2018; Ren et al., 2018).

Wet coating by solution processing is the most conventional method to coat pristine air filter media with anti-viral material (Nguyen et al., 2012; Lou et al., 2014; Hu et al., 2015; Zhong et al., 2015; Cheng et al., 2017). In this method, the filter media needs to be soaked in a solution with a large amount of dispersed anti-viral material. Then, a drying process using a heated air flow is necessary. However, using a heated air flow requires additional cost in terms of time and energy, and often causes deformation of the filter material. By contrast, the aerosol coating method is 
a dry process, in which aerosolized anti-viral material can be deposited directly on the filter media at atmospheric pressure and room temperature conditions. Our group has worked on the fabrication of various anti-viral air filters via the aerosol-coating method. In our previous works (Joe et al., 2014; Ko et al., 2014; Park and Hwang, 2014; Joe et al., 2016), commercially available atomizers were used to coat small-scale filter media $\left(40 \times 40 \mathrm{~mm}^{2}\right)$.

Air filters with filter media that is folded at regular intervals in the form of a zigzag are used in home air cleaners and building HVAC systems to increase their surface area for efficient filtration. Theoretically, these large-scale filter media (over $300 \times 300 \mathrm{~mm}^{2}$ ) can be coated by forced convection with aerosolized anti-viral material. However, commercially available atomizers are operated at flow rates of 2-5 $\mathrm{L} \mathrm{min}^{-1}$ and, therefore, are not suitable to generate the large number of particles required for coating large-scale filter media.

In this work, we designed a laboratory-made atomizer to generate large quantities of aerosolized particles at high flow rate conditions $\left(>200 \mathrm{~L} \mathrm{~min}^{-1}\right)$. The generated anti-viral material $\left(\mathrm{SiO}_{2}-\mathrm{Ag}\right.$ nanoparticles) with liquid droplets was dried via a sheath air flow and used to directly coat a commercial air filter unit. The coated anti-viral air filter was evaluated for filtration efficiency and anti-viral activity against aerosolized MS2 bacteriophage.

\section{METHODS}

\section{Development of a High-volume Flow Atomizer}

The high-volume flow atomizer was designed in our laboratory. The atomizer consisted of a pressure vessel that supplied the particle solution, a multi-hole air nozzle with 70 holes, a multi-hole droplet nozzle with 5 holes, and a mixing chamber with dry air. The holes in both nozzles were $500 \mu \mathrm{m}$ in diameter. Supplemental Information provides the geometrical design and an image of the atomizer (Fig. S1).

Fig. 1 expresses the operational principle of the atomizer. After compressed dry air enters the pressure vessel filled with the anti-viral material solution, the air is accelerated by the multi-hole air nozzle and passes through the mixing chamber. After acceleration using the multi-hole air nozzle, the pressure drops via the Venturi effect. The amount of solution lifted by the pressure difference between the vessel and the nozzle downstream is controlled by a flow control valve. The lifted solution passes through a multi-hole droplet nozzle, resulting in the injection of spray droplets into the air stream. Then, the aerosol flow is mixed with an additional air flow in the mixing chamber for drying and delivering the aerosolized droplets. The pressure difference between the vessel and the nozzle downstream, and the flow rate of the lifted solution were calculated using the following equations:

$$
\begin{aligned}
& P_{N}-P_{B}=\rho_{\text {air }} \cdot\left(V_{u p}^{2}-V_{\text {down }}^{2}\right) \\
& Q_{\text {liq }}=A_{L N} \cdot V_{\text {liq }}=A_{L N} \cdot \sqrt{\frac{2}{\rho_{\text {liq }}} \cdot\left(P_{N}-P_{B}\right)}
\end{aligned}
$$

where $P_{N}$ is the pressure in the nozzle downstream; $P_{B}$ is the pressure in the vessel; $V_{u p}$ and $V_{\text {down }}$ are the air velocities in the nozzle upstream and downstream, respectively; $A_{L N}$

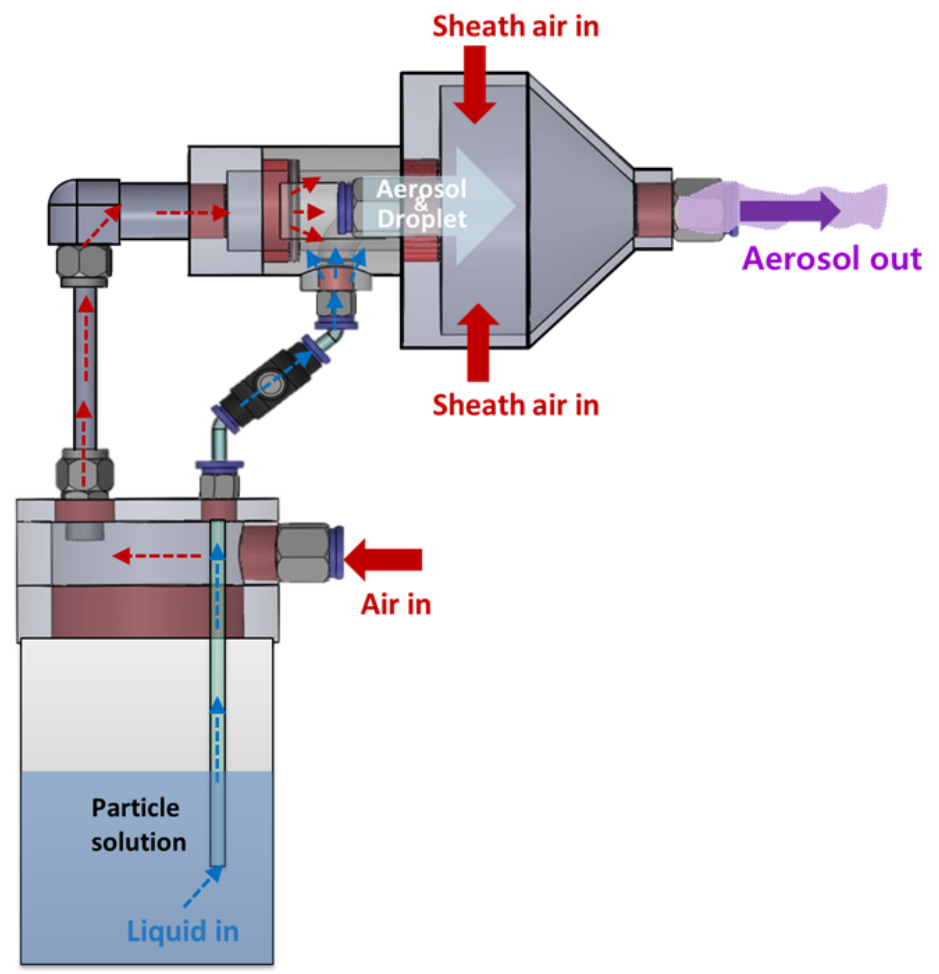

Fig. 1. The operational principle of the high-volume flow atomizer. 
is the hole area of the multi-hole droplet nozzle; $V_{l i q}$ is the velocity of the solution at the multi-hole droplet nozzle; and $\rho_{\text {air }}$ and $\rho_{\text {liq }}$ are the densities of the air and the solution, respectively.

\section{Performance Evaluation of the High-volume Flow Atomizer}

To verify the performance of aerosol particle mass production, the high-volume flow atomizer was evaluated and compared with a conventional atomizer (Single-Jet Atomizer 9302; TSI Inc.). Fig. 2 shows the test schematic. For the performance evaluation of the TSI 9302 atomizer, a mass flow meter (MFM; Mass Flow Meter 4140; TSI Inc.) had $5 \mathrm{~L} \mathrm{~min}^{-1}$ of compressed air cleaned with a filter. Then, the clean air entered the TSI 9302 atomizer that contained $50 \mathrm{~mL}$ of polystyrene latex (PSL) particle (diameter: $0.75 \mu \mathrm{m}$ ) solution. A diffusion dryer was used to eliminate the moisture of the atomized particles. $295 \mathrm{~L} \mathrm{~min}^{-1}$ of additional sheath air flow was used for dilution. For the high-volume flow atomizer, $100 \mathrm{~L} \mathrm{~min}^{-1}$ of clean air entered the atomizer containing the PSL particle solution. Then, the aerosol flow was mixed with $200 \mathrm{~L} \mathrm{~min}^{-1}$ supplied by a commercial air dryer (TX15K; Jemaco, Korea) in the mixing chamber for drying and dispersing the aerosolized droplets.

The air flow containing the PSL particles entered a test duct to measure the total number concentration and size distribution of the particles using an aerodynamic particle sizer (APS Spectrometer 3321; TSI Inc.). A thermohygrometer was installed for temperature and relative humidity $(\mathrm{RH})$ measurements. The generation rate of the TSI 9302 and our atomizer was calculated using the following equation:
$G\left(\right.$ particles $\left.\mathrm{sec}^{-1}\right)=C\left(\right.$ particles $\left.\mathrm{cm}^{-3}\right) \times Q\left(\mathrm{~cm}^{3} \mathrm{sec}^{-1}\right)$

where $G$ is the generation rate, $C$ is the total number concentration of the PSL particles, and $Q$ is the air flow rate.

\section{Coating of a Commercial Air Filter Unit with Anti-viral Materials}

Next, a coating system with a commercial air filter unit was developed (Fig. 3). The compressed clean air (particle free) of $150 \mathrm{~L} \mathrm{~min}^{-1}$ entered the high-volume flow atomizer. $250 \mathrm{~L} \mathrm{~min}^{-1}$ of sheath air from the commercial air dryer was supplied into the mixing chamber to remove any moisture and disperse the aerosolized particles.

In this work, $\mathrm{SiO}_{2}-\mathrm{Ag}$ nanoparticles (NPs) were used as the anti-viral material. The $\mathrm{SiO}_{2}-\mathrm{Ag}$ NPs were synthesized in four steps: 1) the synthesis of $\mathrm{Ag}$ nanoseeds (diameter: $\sim 2 \mathrm{~nm}$ ); 2) the synthesis of $\mathrm{SiO}_{2}$ spheres (diameter: $\sim 400 \mathrm{~nm}$ ); 3 ) the functionalization of $\mathrm{SiO}_{2}$ with an aminopropyl group; and 4) the attachment of Ag nanoseeds on the surface of $\mathrm{SiO}_{2}$ and the growth of the nanoseeds (diameter: $\sim 30 \mathrm{~nm}$ ). The details of the synthesis method were previously introduced in Ko et al. (2014). Based on this synthesis method, about $18 \%$ of the $\mathrm{SiO}_{2} \mathrm{NP}$ (diameter: $\sim 400 \mathrm{~nm}$ ) surface was covered with silver NPs (diameter: $\sim 30 \mathrm{~nm}$ ) $\left(\mathrm{SiO}_{2}: \mathrm{Ag}=1: 300\right.$ in number $)$.

The synthesized anti-viral NPs were delivered via forced convection and coated onto the surface of air filter media. A commercial air filter unit for HVAC systems $(600 \times 300$ $\mathrm{mm}^{2}$; total surface area: $10 \mathrm{~m}^{2}$ ) was used. A condensation particle counter (CPC 3022A; TSI Inc.) was applied to measure the total number concentration of particles. The

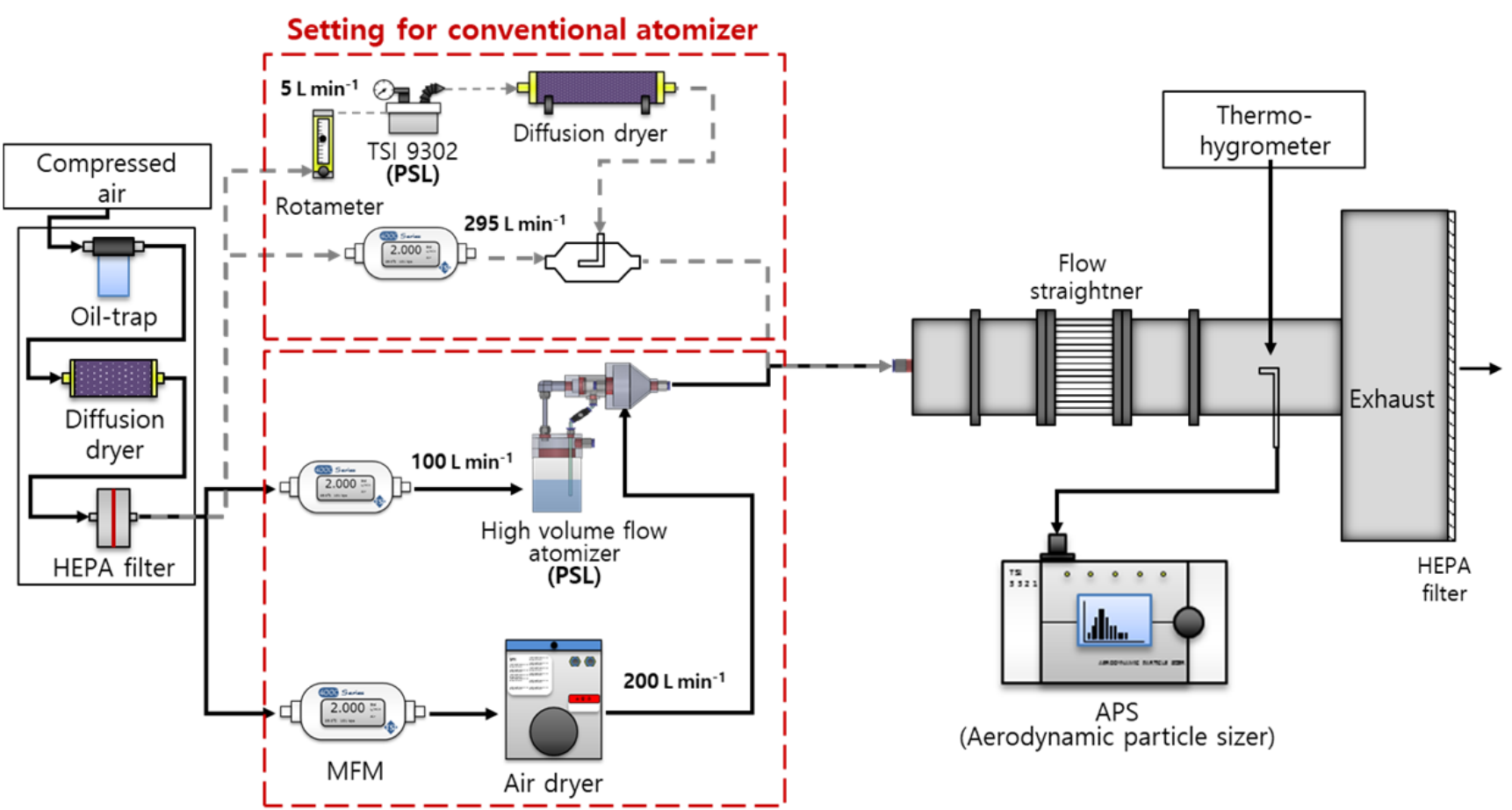

Setting for high volume flow atomizer

Fig. 2. Performance evaluation of the high-volume flow atomizer and TSI 9302 atomizer. 


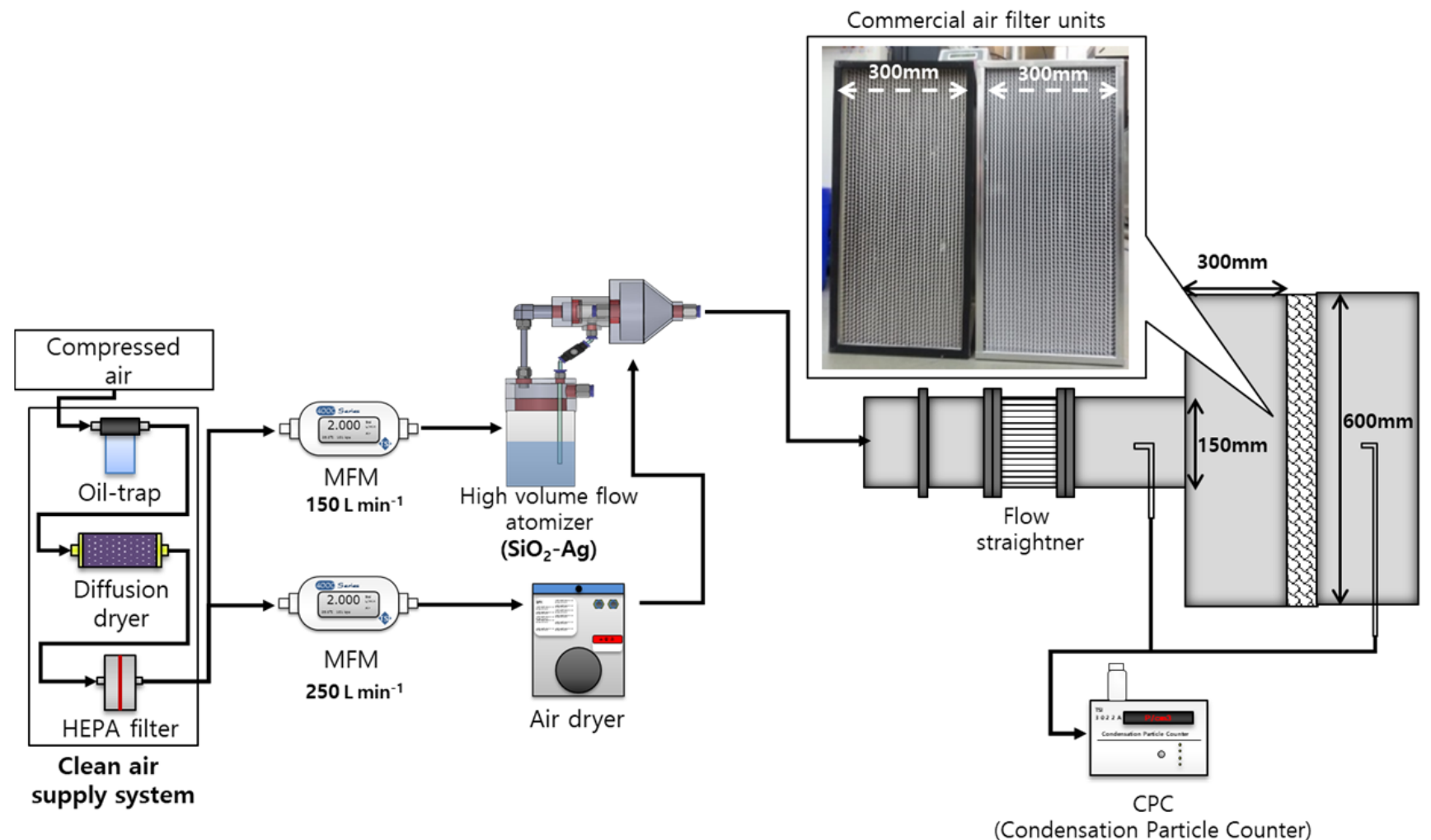

Fig. 3. Schematic for coating a commercial air filter.

coating efficiency $\left(\eta_{\text {coat }}\right)$ and areal density $\left(\rho_{\text {areal }}\right)$ were expressed as follows:

$$
\begin{aligned}
& \eta_{\text {coat }}=1-\frac{C_{\text {down }}}{C_{u p}} \\
& \rho_{\text {coat }}=\frac{\eta_{\text {coat }} \cdot C_{u p} \cdot Q}{A_{\text {filter }}} \cdot t
\end{aligned}
$$

where $C_{u p}$ and $C_{\text {down }}$ are the total number concentrations of the $\mathrm{SiO}_{2}-\mathrm{Ag}$ NPs in the upstream and downstream of the filter, respectively; $A_{\text {filter }}$ is the total surface area of the filter; $Q$ is the flow rate; and $t$ is the coating time. Each test was repeated four times.

The morphology of $\mathrm{SiO}_{2}$-Ag NPs collected on the filter sample was analyzed using a field emission scanning electron microscope (JSM-6701F FE SEM; JEOL).

\section{Evaluation of the Anti-viral Air Filter}

Five locations (P1-P5) were selected from the prepared anti-viral air filter. Each location had an area of $40 \times 40 \mathrm{~mm}^{2}$ and was inserted in the filter holder unit for the filtration of viral aerosols. Fig. 4 shows the test schematic. The media velocity of air was controlled from 0.015 to $0.035 \mathrm{~m} \mathrm{sec}^{-1}$. Then, the pressure drop across the filter sample was measured using a multifunction meter (435-1; Testo, Germany) with varying media velocity.

For the filtration test of the fabricated filter, the MS2 bacteriophage (ATCC 15597-B1) solution was aerosolized using the high-volume flow atomizer. The aerosolized MS2 particles had a mode diameter and total number concentration of $\sim 34.0 \mathrm{~nm}$ and $4.16 \times 10^{6}$ particles $\mathrm{cm}^{-3}$, respectively. Next, the bioaerosols passed through a filter sample that was inserted in the test duct. Two sampling points were positioned before and after the filter sample to measure the concentrations upstream $\left(N_{u p}\right)$ and downstream $\left(N_{\text {down }}\right)$ of the aerosolized viral particles. A scanning mobility particle sizer (SMPS) system, comprising an aerosol charge neutralizer (Soft X-ray 4530; HCT, Korea), a differential mobility analyzer (DMA 3081; TSI Inc.), a CPC (3022A; TSI Inc.), and a classifier controller (Electrostatic Classifier 3080; TSI Inc.), was used. The filtration efficiency $\left(\eta_{\text {filt }}\right)$ was determined by the following equation:

$\eta_{\text {filt }}=1-\frac{N_{\text {down }}}{N_{u p}}$

For the anti-viral test of the filter, a plaque assay was performed. The aerosolized MS2 particles were collected onto the surface of a filter sample for $15 \mathrm{~min}$. Then, the collected particles were released from the filter sample to a urea-arginine phosphate buffer (U-APB) solution for $10 \mathrm{~min}$. Finally, $0.1 \mathrm{~mL}$ of U-APB solution, including released viral particles, was added to $0.3 \mathrm{~mL}$ of Escherichia coli (host bacteria) C-3000 (ATCC 15597) and $29 \mathrm{~mL}$ of soft agar medium (tryptic soy agar). The mixture was incubated in a petri-dish for $24 \mathrm{~h}$ at the proper temperature and humidity; then, the number of cultured viral particles was counted (in plaque forming units (PFUs)). The anti-viral 


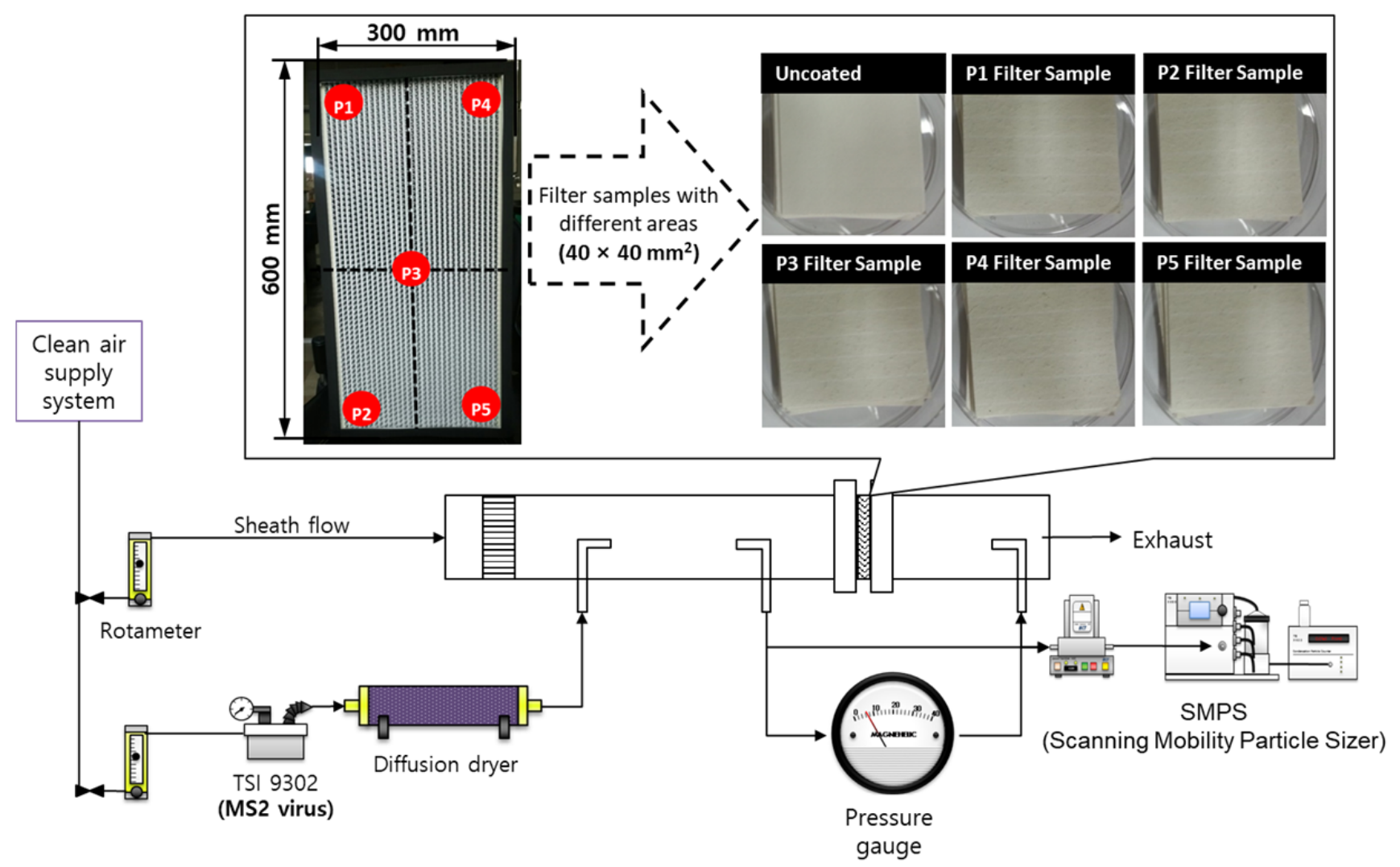

Fig. 4. Evaluation of the pressure drop and filtration efficiency for the MS2 virus.

efficiency $\left(\eta_{\text {anti }}\right)$ was determined as:

$\eta_{\text {anti }}=1-\frac{P F U_{\text {sample }}}{P F U_{\text {uncoated }}}$

where $P F U$ denotes the viral particle concentration (plaques per unit volume $\left(\mathrm{m}^{3}\right)$ ), and the subscripts sample and uncoated denote the fabricated and uncoated filter sample, respectively.

\section{RESULTS AND DISCUSSION}

\section{Evaluation of the High-volume Flow Atomizer}

Fig. 5 compares the generation rates of PSL particles between our atomizer and the TSI 9302 atomizer. While the generation rate of the TSI 9302 was $\sim 3,900$ particles $\mathrm{sec}^{-1}$, the generation rate of the high-volume flow atomizer was $\sim 34,000$ particles $\mathrm{sec}^{-1}$. The particle size distributions obtained with the two atomizers are provided in Supplemental Information (Fig. S2). The mode diameter was $\sim 0.78 \mu \mathrm{m}$, which matched the original size of the PSL particles $(\sim 0.75 \mu \mathrm{m})$. However, the total number concentrations of the aerosolized PSL particles were different, with 424.2 and 35.5 particles per unit air volume $\left(\mathrm{cm}^{3}\right)$ for the highvolume flow atomizer and TSI 9302, respectively. The temperature and $\mathrm{RH}$ in the test duct were $25.5^{\circ} \mathrm{C}$ and $33 \%$, respectively.

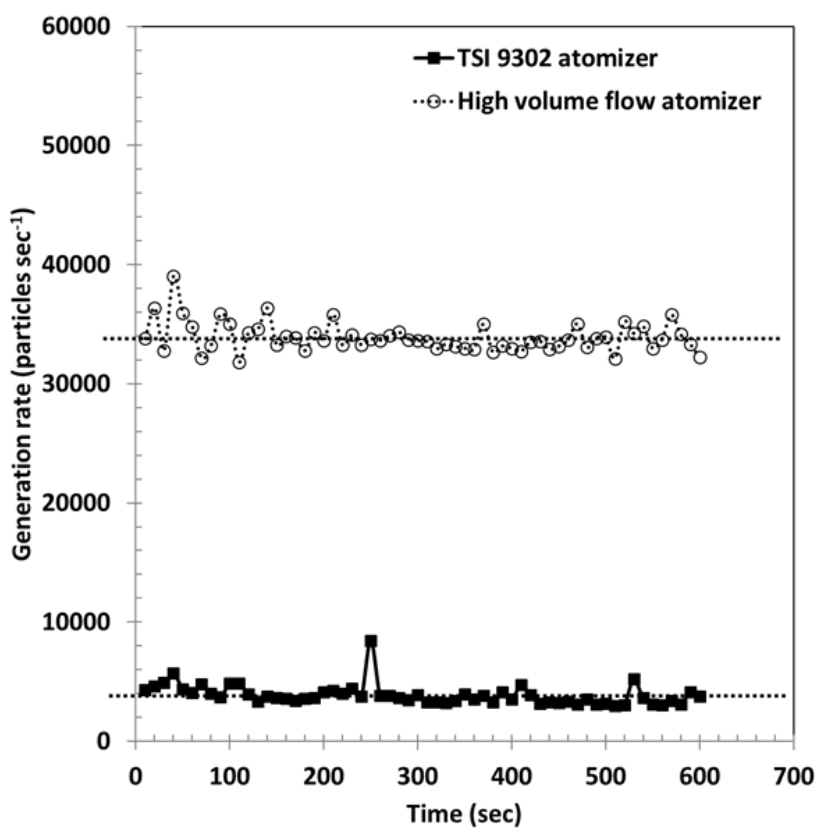

Fig. 5. Comparison of the particle generation rates between the high-volume flow atomizer and TSI 9302 atomizer.

\section{Coating a Commercial Air Filter Unit with Anti-viral Materials}

The $\mathrm{SiO}_{2}-\mathrm{Ag}$ nanoparticles were coated on the commercial air filter unit for $32.3 \mathrm{~h}$. The coating efficiencies of the selected locations (P1-P5) for $\mathrm{SiO}_{2}-\mathrm{Ag}$ NPs were calculated 
through Eq. (4). The areal density of the coating for each filter sample was calculated using Eq. (5) with the given coating time. Table 1 shows the corresponding results. The coating efficiencies of all filter samples, except P1, were higher than $99.6 \%$. The P1 filter sample had approximately $98 \%$ coating efficiency. Fig. 6 shows SEM images taken at different locations on the filter. The dendritic morphology of the $\mathrm{SiO}_{2}-\mathrm{Ag}$ NPs was observed on the filter fibers (Fig. 6(a)). The particles were well dispersed on the filter surface, and there were no significant differences between the different filter samples (Figs. 6(b)-6(f)).

\section{Evaluation of the Fabricated Anti-viral Air Filter}

Table 2 shows the pressure drops for the uncoated and coated air filters with different media velocities for air flow. For each filter sample, the pressure drop increased with the media velocity. However, there were no significant differences in pressure drop with various filter samples. In addition, the coated $\mathrm{SiO}_{2}-\mathrm{Ag}$ NPs had no effect on the pressure drop across the filter.

Fig. 7 shows the filtration efficiencies of different filter samples. For each filter sample, the filtration efficiency decreased as the media velocity increased. Brownian motion dominates the filtration mechanism for nanoparticles, such as viral particles. Therefore, for a given particle size, the filtration efficiency due to diffusion increases with decreasing media velocity (Hinds, 1999).

Furthermore, as shown in Fig. 7, the filtration efficiency

Table 1. Coating characteristics of different filter samples.

\begin{tabular}{lllll}
\hline Sample & $\begin{array}{l}\text { Inlet particle concentration } \\
(\text { particles cm }\end{array}$ & $\begin{array}{l}\text { Outlet particle concentration } \\
\left(\text { particles } \mathrm{cm}^{-3}\right)\end{array}$ & $\begin{array}{l}\text { Coating efficiency } \\
(\%)\end{array}$ & $\begin{array}{l}\text { Areal density of the coating } \\
(\text { particles cm }\end{array}$ \\
\hline P1 & & 563 & $97.75 \pm 5$ & $9.78 \times 10^{7}$ \\
P2 & & 69 & $99.87 \pm 0.07$ & $9.99 \times 10^{7}$ \\
P3 & 25,026 & 32 & $99.72 \pm 0.16$ & $9.97 \times 10^{7}$ \\
P4 & & 96 & $99.69 \pm 0.17$ & $9.97 \times 10^{7}$ \\
P5 & & 78 & $99.62 \pm 0.23$ & $9.96 \times 10^{7}$ \\
\hline
\end{tabular}
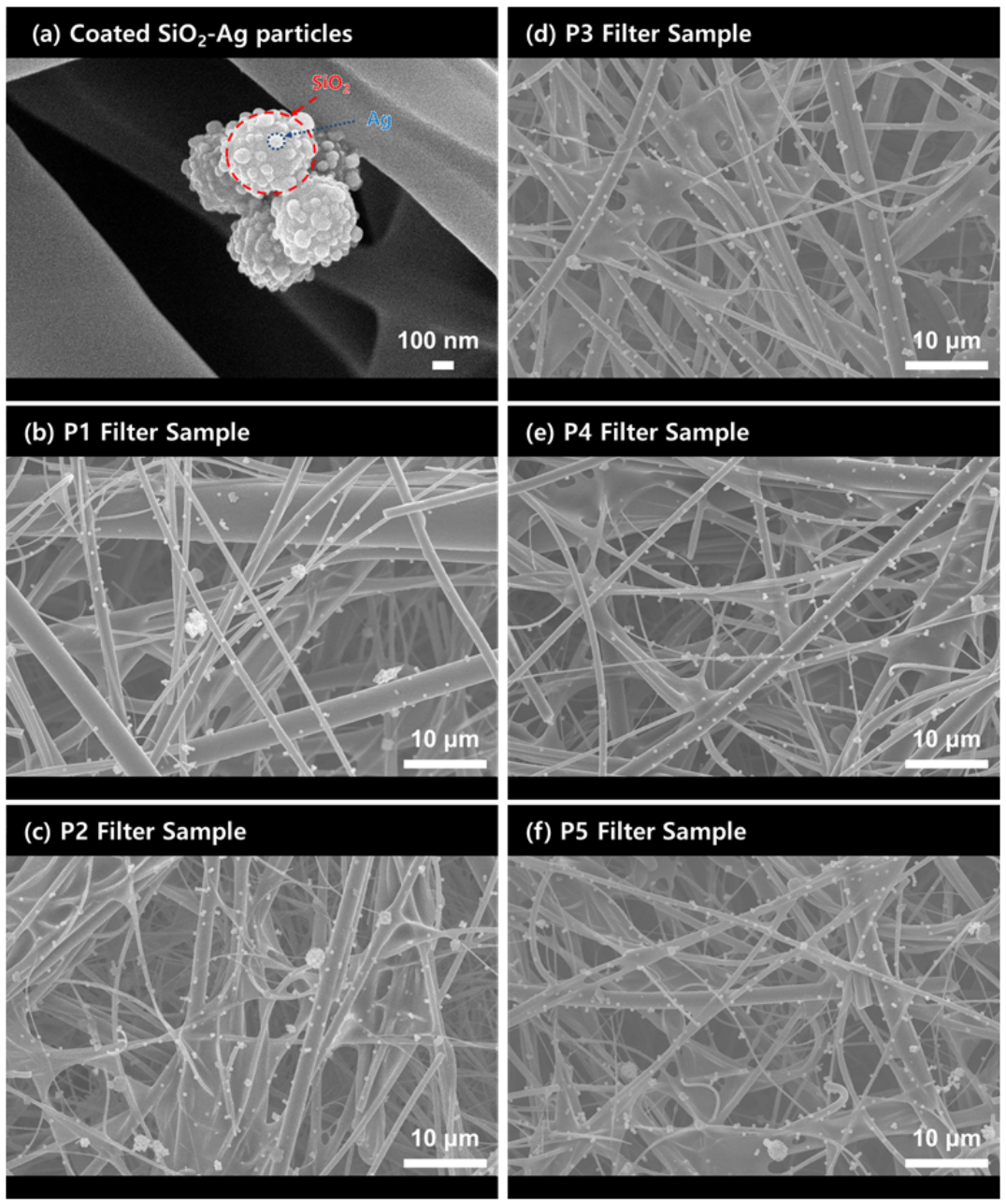

Fig. 6. FE-SEM images taken in different areas of the $\mathrm{SiO}_{2}-\mathrm{Ag}$ coated filter. 
Table 2. Pressure drops of the filter samples.

\begin{tabular}{|c|c|c|c|c|c|c|}
\hline \multirow{2}{*}{ Vel. $\left(\mathrm{m} \mathrm{sec}^{-1}\right)$} & \multicolumn{6}{|c|}{ Pressure drop $(\mathrm{Pa})$} \\
\hline & Uncoated & P1 & $\mathrm{P} 2$ & P3 & P4 & P5 \\
\hline 0.016 & 22 & 22 & 23 & 22 & 21 & 23 \\
\hline 0.021 & 34 & 34 & 36 & 34 & 36 & 36 \\
\hline 0.026 & 47 & 46 & 48 & 46 & 47 & 46 \\
\hline 0.031 & 61 & 60 & 62 & 58 & 61 & 60 \\
\hline 0.036 & 75 & 73 & 76 & 75 & 74 & 76 \\
\hline
\end{tabular}

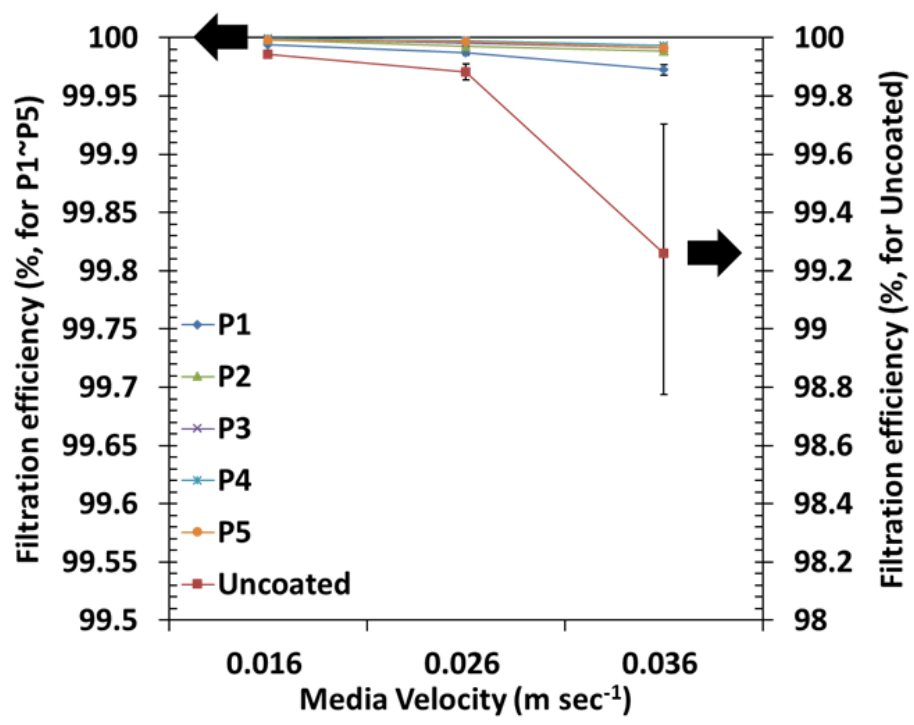

Fig. 7. Filtration efficiencies of the $\mathrm{SiO}_{2}-\mathrm{Ag}$ coated filter.

Table 3. Anti-viral efficiencies of the $\mathrm{SiO}_{2}-\mathrm{Ag}$ coated filter.

\begin{tabular}{llllll}
\hline & P1 & P2 & P3 & P4 & P5 \\
\hline$\eta_{\text {anti }}(\%)$ & $82.0 \pm 2.31$ & $91.1 \pm 3.39$ & $93.4 \pm 3.88$ & $96.0 \pm 1.25$ & $96.1 \pm 2.19$ \\
\hline
\end{tabular}

increased with the coated $\mathrm{SiO}_{2}-\mathrm{Ag}$ NPs for a given media velocity. This trend is consistent with that of previous studies (Brown et al., 1988; Joe et al., 2014). However, there were no significant differences in the filtration efficiency between various filter samples. Although the filter sample of P1 had a lower filtration efficiency than that of the other samples owing to a lower amount of coating material, the average for the filtration efficiencies was over $99.99 \%$.

Table 3 shows the results of the anti-viral test with different filter samples (P1-P5). The anti-viral efficiency of $\mathrm{P} 1$ was about $82 \%$, whereas those of other samples were higher than $90 \%$. This difference was attributed to the lower quantity of $\mathrm{SiO}_{2}-\mathrm{Ag} \mathrm{NPs}$ on P1.

\section{CONCLUSIONS}

In this work, a high-volume flow atomizer was designed to generate anti-viral material $\left(\mathrm{SiO}_{2}-\mathrm{Ag} \mathrm{NPs}\right)$ at a rate 8.5 times higher than that of a conventional system. A commercial air filter (larger than $600 \times 300 \mathrm{~mm}^{2}$ ) was coated with the aerosolized $\mathrm{SiO}_{2}-\mathrm{Ag}$ NPs via a dry aerosolcoating method. The filter performance (the pressure drop, filtration efficiency, and anti-viral activity) was then tested using aerosolized MS2 bacteriophage particles. When the areal density of the coating was $1.0 \times 10^{8}$ particles $\mathrm{cm}^{-2}$, the average anti-viral effectiveness of the air filter was $\sim 92 \%$. The $\mathrm{SiO}_{2}-\mathrm{Ag}$ NP coating did not affect the pressure drop. The filtration efficiency increased with the number of $\mathrm{SiO}_{2}-\mathrm{Ag}$ NPs for a given media velocity.

\section{ACKNOWLEDGMENTS}

This research was supported by Basic Science Research Program through the National Research Foundation of Korea (NRF) funded by the Ministry of Science, ICT, and Future Planning (NRF-2018R1A2A1A05020683).

\section{SUPPLEMENTARY MATERIAL}

Supplementary data associated with this article can be found in the online version at http://www.aaqr.org.

\section{REFERENCES}

Brown, R.C., Wake, D., Gray, R., Blackford, D.B. and Bostock, G.J. (1988). Effect of industrial aerosols on the 
performance of electrically charged filter material. Ann. Occup. Hyg. 32: 271-294.

Byeon, J.H., Yoon, K.Y., Park, J.H. and Hwang, J. (2007). Characteristics of electroless copper-deposited activated carbon fibers for antibacterial action and adsorptiondesorption of volatile organic compounds. Carbon 45: 2313-2316.

Cecchini, C., Verdenelli, M.C., Orpianesi, C., Dadea, G.M. and Cresci, A. (2004). Effects of antimicrobial treatment on fiberglass-acrylic filters. J. Appl. Microbiol. 97: 371377.

Chen, P.S., Lin, C.K., Tsai, F.T., Yang, C.Y., Lee, C.H., Liao, Y.S., Yeh, C.Y., King, C.C., Wu, J.L., Wang, Y.C. and Lin, K.H. (2009). Quantification of airborne influenza and avian influenza virus in a wet poultry market using a filter/real-time qPCR method. Aerosol Sci. Technol. 43: 290-297.

Cheng, M.M., Huang, L.J., Wang, Y.X., Tang, J.G., Wang, Y., Zhao, Y.C., Liu, G.F., Zhang, Y., Kipper, M.J., Belfiore, L.A. and Ranil, W.S. (2017). Recent developments in graphene-based/nanometal composite filter membranes. RSC Adv. 7: 47886-47897.

Choi, D.Y., Heo, K.J., Kang, J., An, E.J., Jung, S.H., Lee, B.U., Lee, H.M. and Jung, J.H. (2018). Washable antimicrobial polyester/aluminum air filter with a high capture efficiency and low pressure drop. J. Hazard. Mater. 351: 29-37.

Fabian, P., McDevitt, J.J., DeHaan, W.H., Fung, R.O., Cowling, B.J., Chan, K.H., Leung, G.M. and Milton, D.K. (2008). Influenza virus in human exhaled breath: an observational study. PLoS One 3: e2691.

Hinds, W.C. (1999). Aerosol technology: Properties, behavior, measurement of airborne particles. John Wiley \& Sons.

Hu, J., Zhong, Z., Zhang, F., Xing, W., Low, Z.X. and Fan, Y. (2015). Coating of $\mathrm{ZnO}$ nanoparticles onto the inner pore channel surface of $\mathrm{SiC}$ foam to fabricate a novel antibacterial air filter material. Ceram. Int. 41: 70807090.

Joe, Y.H., Park, D.H. and Hwang, J. (2016). Evaluation of $\mathrm{Ag}$ nanoparticle coated air filter against aerosolized virus: Anti-viral efficiency with dust loading. J. Hazard. Mater. 301: 547-553.

Joe, Y.H., Woo, K. and Hwang, J. (2014). Fabrication of an anti-viral air filter with $\mathrm{SiO}_{2}-\mathrm{Ag}$ nanoparticles and performance evaluation in a continuous airflow condition. J. Hazard. Mater. 280: 356-363.

Ko, Y.S., Joe, Y.H., Seo, M., Lim, K., Hwang, J. and Woo, K. (2014). Prompt and synergistic antibacterial activity of silver nanoparticle-decorated silica hybrid particles on air filtration. J. Mater. Chem. B 2: 6714-6722.

Lee, N., Hui, D., Wu, A., Chan, P., Cameron, P., Joynt, G.M., Ahuja, A., Yung, M.Y., Leung, C. B., To, K.F., Lui, S.F., Szeto, C.C., Chung, S. and Sung, J.Y. (2003). A major outbreak of severe acute respiratory syndrome in Hong Kong. New Engl. J. Med. 348: 1986-1994.

Leung, W.W.F., Hung, C.H. and Yuen, P.T. (2009). Experimental investigation on continuous filtration of sub-micron aerosol by filter composed of dual-layers including a nanofiber layer. Aerosol Sci. Technol. 43: 1174-1183.

Loeb, M., Dafoe, N., Mahony, J., John, M., Sarabia, A., Glavin, V., Webby, R., Smieja, M., Earn, D.J.D., Chong, S., Webb, A. and Water, S.D. (2009). Surgical mask vs N95 respirator for preventing influenza among health care workers. JAMA 302: 1865-1871.

Lou, Y., Liu, G., Liu, S., Shen, J. and Jin, W. (2014). A facile way to prepare ceramic-supported graphene oxide composite membrane via silane-graft modification. Appl. Surf. Sci. 307: 631-637.

Maus, R., Goppelsröder, A. and Umhauer, H. (2001). Survival of bacterial and mold spores in air filter media. Atmos. Environ. 35: 105-113.

Miaśkiewicz-Peska, E. and Łebkowska, M. (2011). Effect of antimicrobial air filter treatment on bacterial survival. Fibres Text. East. Eur. 19: 73-77.

Nguyen, D.D., Tai, N.H., Lee, S.B. and Kuo, W.S. (2012). Superhydrophobic and superoleophilic properties of graphene-based sponges fabricated using a facile dip coating method. Energy Environ. Sci. 5: 7908-7912.

Oberdörster, G. and Utell, M.J. (2002). Ultrafine particles in the urban air: To the respiratory tract--and beyond? Environ. Health Perspect. 110: A440-A441.

Park, K.T. and Hwang, J. (2014). Filtration and inactivation of aerosolized bacteriophage MS2 by a CNT air filter fabricated using electro-aerodynamic deposition. Carbon 75: 401-410.

Park, S.J. and Jang, Y.S. (2003). Preparation and characterization of activated carbon fibers supported with silver metal for antibacterial behavior. J. Colloid Interface Sci. 261: 238-243.

Pokhum, C., Intasanta, V., Yaipimai, W., Subjalearndee, N., Srisitthiratkul, C., Pongsorrarith, V., Phanomkate, N. and Chawengkijwanich, C. (2018). A facile and costeffective method for removal of indoor airborne psychrotrophic bacterial and fungal flora based on silver and zinc oxide nanoparticles decorated on fibrous air filter. Atmos. Pollut. Res. 9: 172-177.

Ren, T., Dormitorio, T.V., Qiao, M., Huang, T.S. and Weese, J. (2018). N-halamine incorporated antimicrobial nonwoven fabrics for use against avian influenza virus. Vet. Microbiol. 218: 78-83.

Sawyer, M.H., Chamberlain, C.J., Wu, Y.N., Aintablian, N. and Wallace, M.R. (1994). Detection of VaricellaZoster virus DNA in air samples from hospital rooms. $J$. Infect. Dis. 169: 91-94.

Sim, K.M., Park, H.S., Bae, G.N. and Jung, J.H. (2015). Antimicrobial nanoparticle-coated electrostatic air filter with high filtration efficiency and low pressure drop. Sci. Total Environ. 533: 266-274.

Smith, G.J., Vijaykrishna, D., Bahl, J., Lycett, S.J., Worobey, M., Pybus, O.G., Ma, S.K., Cheung. C.L., Raghwani, J., Bhatt, S., Peiris, J.S., Guan, Y. and Rambaut, A. (2009). Origins and evolutionary genomics of the 2009 swine-origin H1N1 influenza A epidemic. Nature 459: 1122-1125.

Stelzer-Braid, S., Oliver, B.G., Blazey, A.J., Argent, E., Newsome, T.P., Rawlinson, W.D. and Tovey, E.R. 
(2009). Exhalation of respiratory viruses by breathing, coughing, and talking. J. Med. Virol. 81: 1674-1679.

Taylor, M., McCollister, B. and Park, D. (2016). Highly bactericidal polyurethane effective against both normal and drug-resistant bacteria: Potential use as an air filter coating. Appl. Biochem. Biotechnol. 178: 1053-1067.

Verdenelli, M.C., Cecchini, C., Orpianesi, C., Dadea, G.M. and Cresci, A. (2003). Efficacy of antimicrobial filter treatments on microbial colonization of air panel filters. J. Appl. Microbiol. 94: 9-15.

Wells, W.F. (1955). Airborne contagion and air hygiene: An ecological study of droplet infections. Harvard
University Press, Cambridge, MA.

Yang, W., Elankumaran, S. and Marr, L.C. (2011). Concentrations and size distributions of airborne influenza A viruses measured indoors at a health centre, a day-care centre and on aeroplanes. J. R. Soc. Interface 8: 1176-1184.

Received for review, April 20, 2019

Revised, April 20, 2019

Accepted, April 26, 2019 